\title{
ANÁLISE DO DESPERDÍCIO DE HORTIFRÚTIS PROVENIENTE DA AGRICULTURA FAMILIAR NO MUNICÍPIO DE CAPISTRANO-CE
}

\author{
Rafaelly de Aguiar da Silva* \\ Lailla Sabrina Queiroz Nazareno* \\ Francisco Acacio de Sousa ${ }^{\text {*t+ }}$ \\ Maria do Socorro Moura Rufino ${ }^{\star *+*}$
}

\begin{abstract}
RESUMO: Os altos índices de desperdício de alimentos do setor hortifrúti é algo que pode ser observado atualmente ao longo de todo processo de produção, principalmente quando se trata de agricultores de base familiar com poucos recursos financeiros e tecnológicos disponíveis. Este desperdício abrange desde a produção, passando pelo transporte, armazenamento, distribuição e industrialização, até chegar ao consumidor final. Nesse contexto, o presente trabalho objetivou analisar esta situação no âmbito da agricultura familiar na cidade de Capistrano$\mathrm{CE}$, a fim de identificar os principais fatores responsáveis pela referida problemática. Metodologicamente, esse trabalho adotou uma abordagem qualitativa de cunho descritivo, com levantamento de dados secundários junto aos órgãos públicos, onde foi possível identificar as principais informações quanto à produção agrícola local, permitindo a reflexão do pesquisador, a descrição e interpretação do problema pesquisado, bem como a contribuição do trabalho para a literatura. Além disso, foram realizadas visitas in loco com o intuito de identificar 0 processo da cadeia produtiva desde 0 campo à comercialização. 0 s resultados encontrados evidenciaram um grande potencial de mercado para 0 setor hortifrúti a ser explorado pelos agricultores familiares; entretanto, há desperdício de frutas e hortaliças ao longo de toda a cadeia produtiva, ocorrendo maior volume de perdas na pós-colheita, por vários fatores: desde armazenamento inadequado, más condições de transporte, até 0 desconhecimento de tecnologias de processamento e questões relacionadas à educação do consumidor final.
\end{abstract}

PALAVRAS-CHAVE: Hortifrútis; Desperdício; Agricultura familiar.

\section{VEGETABLE AND FRUIT WASTES FROM FAMILY AGRICULTURE IN CAPISTRANO, BRAZIL}

ABSTRACT: High levels of vegetable and fruit waste has been reported throughout the whole production process, especially among farmers on family farms characterized by few financial and technological resources. Waste occurs throughout production, transport, storage, distribution and industrialization till the final consumer. Current qualitative and descriptive study investigates the situation in family agriculture in Capistrano CE Brazil, and identifies the main factors by analyzing secondary data produced by government organs. Main information on local agricultural production was identified to describe and interpret the issue and contributed towards specialized literature. Visits occurred in loco to identify the productive chain from farm to market. Results showed great market potential for the vegetable and fruit sector that may be exploited by family farmers. However, fruit and vegetable waste throughout the production chain exists, with great post-harvest losses due to inadequate storage, bad transport conditions, ignorance on processing technology and issues related to the education of the final consumer.

KEYWORDS: Vegetable and fruits; Wastes; Family agriculture.

\footnotetext{
* Graduada em Agronomia na Universidade Integração Internacional da Lusofonia Afro-Brasileira (UNILAB), Brasil.

** Graduanda do curso de Agronomia pela Universidade da Integração Internacional da Lusofonia Afro-Brasileira (UNILAB); Participante do Grupo de pesquisa POLIFIBAN/CNPq, Brasil

*** Graduando em Agronomia na Universidade Integração Internacional da Lusofonia Afro-Brasileira (UNILAB); Bolsista pelo programa PIBICT/FUNCAP, Brasil

${ }^{* * * *}$ Doutora em Fitotecnia pela UFERSA com estágio no Exterior em Bioquímica da Nutrição no Dept. de Metabolismo e Nutrição (ICTAN/CSIC), da Espanha; Docente permanente do Programa de Mestrado Acadêmico em Sociobiodiversidade e Tecnologias Sustentáveis (UNILAB); Docente Efetiva da Universidade da Integração Internacional da Lusofonia Afro-Brasileira (UNILAB); , Brasil.
} 


\section{INTRODUÇÃo}

Em todo o mundo, milhões de pessoas vivem em um nível elevado de pobreza e fome. Durante muito tempo, a fome esteve ligada apenas à escassez de alimentos, porém, estudos e observações comprovam que esta representa apenas um dos fatores que levam a essa condição, a má distribuição, 0 desperdício, as desigualdades sociais, entre outros, também contribuindo para essa situação (PRIM, 2003).

Dados de 2012 da Organização das Nações Unidas para Alimentação e Agricultura (FA0) informam que, por ano, 1,3 bilhão de toneladas de comida são jogadas fora. 0 Brasil aparece no levantamento, como 0 país onde $70 \%$ dos alimentos consumidos são provenientes da agricultura familiar (BICALHO; LIMA, 2013).

A cada 10 toneladas de alimentos produzidos no Brasil, 4 toneladas chegam ao consumidor, o que representa 39 mil toneladas de comida que terminam no lixo diariamente. Todo esse alimento desperdiçado poderia alimentar cerca de 19 milhões de pessoas todos os dias, proporcionando as refeições básicas: café da manhã, almoço e jantar. Em termos financeiros, 0 dado representa um montante de $\mathrm{R} \$ 12$ bilhões anuais jogados fora. Esse é um dos fatores que explica o porquê de, apesar da grande produção de alimentos, o país encontrar-se, atualmente, na sexta posição no ranking mundial de desnutrição, com milhares de pessoas em situação de insegurança alimentar, ou seja, aquelas que não têm as fontes de nutrientes suficientes e preservados (BICALHO; LIMA, 2013).

Para minimizar 0 desperdício, algumas medidas podem ser propostas, tais como a reeducação e treinamento de todo o pessoal envolvido (desde 0 campo até a pós-colheita), o manejo adequado e a melhoria no tratamento, antes, durante e depois da produção, sobretudo com frutas e hortaliças, que apresentam perdas, aqui no Brasil, entre $30 \%$ e $35 \%$, respectivamente (ROCHA et al., 2009).

Em um mercado cada vez mais competitivo, a preocupação tem sido a de obter um diferencial, que crie novas opções de renda ao produtor e agregue valor aos produtos agrícolas. Para isso, é necessário um bom planejamento do empreendimento, assim como conhecimentos técnicos acerca de todo o processo produtivo, desde a colheita de frutos de qualidade, até a comercialização do produto final (RICARTE et al, 2008).

Dentre as seis macrorregiões do Estado do Ceará, podemos destacar as Serras Úmidas/Baturité, que é uma formação do relevo local, também conhecida como Maciço de Baturité. Localizada no centronorte do Estado, está distribuída pelo território de 12 municípios: Canindé, Caridade, Aratuba, Mulungu, Guaramiranga, Pacoti, Palmácia, Itapiúna, Capistrano, Baturité, Redenção e Acarape. É uma das regiões de maiores índices pluviométricos do Estado, tendo como climas predominantes o tropical quente subúmido, nas áreas de menor altitude; 0 tropical quente úmido, nas altitudes intermediárias; e o tropical subquente úmido, nas altitudes mais elevadas. Os tipos fitoecológicos predominantes são floresta subperenifólia tropical pluvio-nebular (ou mata úmida serrana) nas maiores altitudes; floresta subcaducifólia tropical pluvial (ou mata seca) nas regiões de altitude intermediária; e caatinga arbustiva densa nas regiões de menor altitude. Funciona também como divisor de águas das bacias hidrográficas dos rios Curu, Choró e Pacoti.

0 foco do trabalho aqui apresentado está na região do Maciço de Baturité, CE, onde podem ser encontradas várias espécies frutíferas de interesse local, no qual o uso sustentado destas se mostra como uma excelente opção para agregar valor aos recursos naturais disponíveis, aumentando a renda das pequenas comunidades rurais e favorecendo a preservação destas espécies.

0 município de Capistrano está localizado na região do Maciço de Baturité, a $140 \mathrm{~km}$ de distância da capital Fortaleza. Capistrano tem uma população de 17.062 habitantes, com uma economia predominantemente agrícola, conforme estimativa realizada em novembro de 2010 , do Instituto Brasileiro de Geografia e Estatística (IBGE, 2010).

Diante das referidas considerações o presente estudo teve como objetivo analisar o desperdício de 
produtos hortifrútis produzidos pela agricultura familiar na cidade de Capistrano, identificando os principais fatores e causas do desperdício na cadeia produtiva.

\section{METODOLOGIA}

A avaliação das perdas de hortifrútis foi realizada por meio de levantamento junto ao principal equipamento de varejo na cidade de CapistranoCE. De acordo com a National Academy of Sciences (1982), avaliação constitui uma aproximação das perdas dos alimentos, se contrapondo à medição que é um processo mais preciso e objetivo. 0 uso desse termo tem implícito, portanto, um grau de subjetividade decorrente da dificuldade de obtenção de informação mais precisa.

0 conceito de perda, nesta pesquisa, se baseia em Chitarra e Chitarra (2005), que a define como reduções na quantidade física do produto disponível para o consumo, que podem vir acompanhadas por uma redução na qualidade, diminuindo o valor comercial ou nutritivo do produto.

Esta pesquisa adota uma abordagem qualitativa, que conforme Minayo (2001), a pesquisa qualitativa trabalha com 0 universo de significados, motivos, aspirações, crenças, valores e atitudes, 0 que corresponde a um espaço mais profundo das relações, dos processos e dos fenômenos que não podem ser reduzidos à operacionalização de variáveis. Quanto aos objetivos, a pesquisa caracteriza-se como descritiva, a qual exige do investigador uma série de informações sobre 0 que deseja pesquisar. Esse tipo de estudo pretende descrever os fatos e fenômenos de determinada realidade (TRIVIÑOS, 1987).

A pesquisa qualitativa adotou 0 levantamento de dados secundários junto aos órgãos públicos, onde foi possível identificar as principais informações quanto à produção agrícola local, permitindo a reflexão do pesquisador, a descrição e interpretação do problema pesquisado, bem como a contribuição do trabalho para a literatura.

Foram considerados sete tipos de hortifrútis mais produzidos na região, sendo estes: banana (Musa spp), maracujá (Passiflora sp), mamão (Carica papaya), cajá (Spondias mombin), acerola (Malpighia emarginata), tomate (Solanum lycopersicum) e jerimum (Cucurbita spp).

0 equipamento varejista pesquisado foi a feira-livre, conceituado segundo Barros (1978), como equipamento varejista móvel, cuja característica principal é a circulação de instalações provisórias nas vias públicas. 0 feirante tem possibilidades de realizar compras diretas do produtor (às vezes é a mesma pessoa), permitindo-Ihe vender ao consumidor a preços mais convenientes.

Para avaliação das perdas pós-colheita de cada produto, foram utilizados os seguintes parâmetros e informações: indicadores de classificação das perdas de hortifrútis; uso de caixas para o transporte do campo à feira local; exposição dos produtos a variações de temperatura, umidade e radiação solar e logística de organização dos hortifrútis comercializados na feira livre em Capistrano-Ce.

\section{RESULTADO E DISCUSSÃO}

0 Gráfico 1 apresenta os principais indicadores de perdas pós-colheita dos hortifútis desde a produção até sua comercialização. Dentre estes, 0 principal causador de perdas é 0 armazenamento inadequado $(40 \%)$, seguido pelas más condições de transporte $(30 \%)$. 


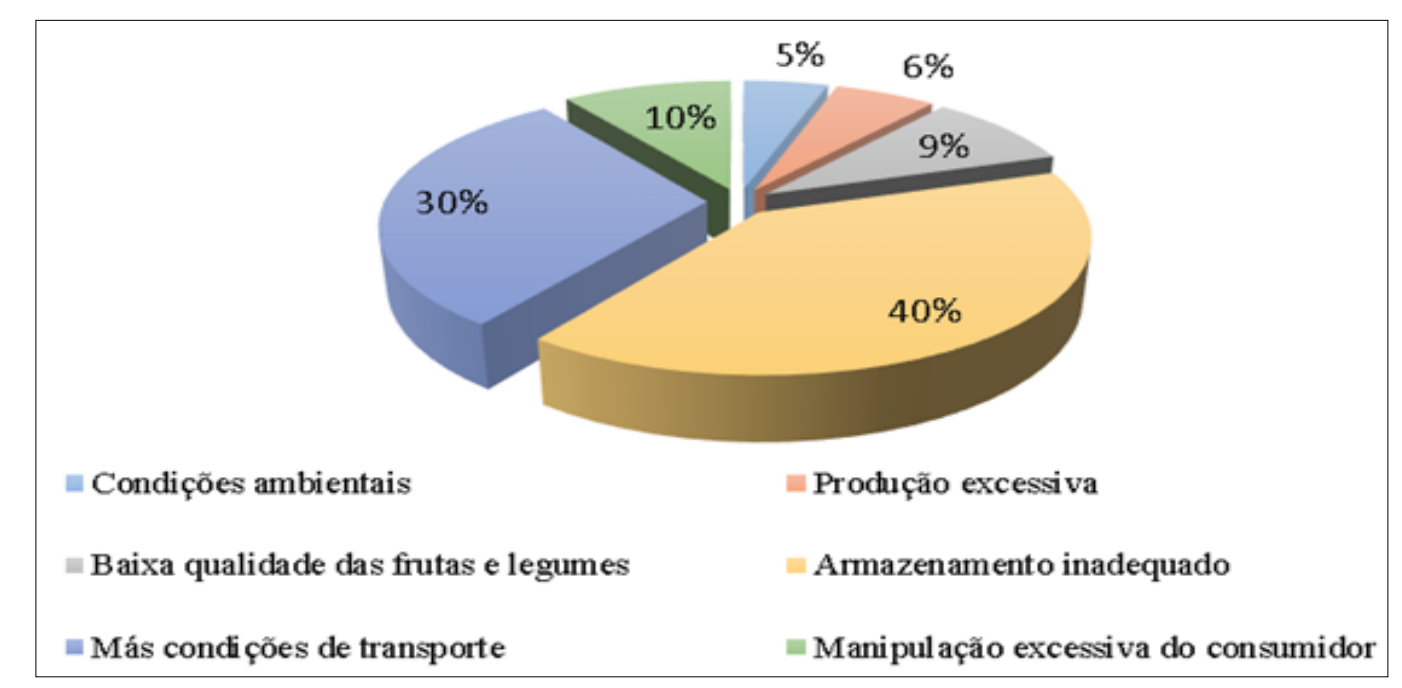

Gráfico 1. Indicadores de perdas pós-colheita de hortifrútis comercializados na feira livre em Capistrano-CE Fonte: Autor

As perdas ocorridas no início da cadeia produtiva são bem significativas, resultantes da falta de planejamento e força de trabalho capacitada para a execução das atividades. Corrobora-se, assim, com 0 que afirmam Martins; Farias (2002), que o desperdício ou o melhor aproveitamento de todos os recursos a serem produzidos, inicia-se muito antes de ser realizada a colheita, pois é na fase de planejamento das culturas que se tomam algumas decisões que terão interferência futura em todo processo da cadeia produtiva.

Construindo-se uma ordem dos acontecimentos, pode-se dizer que as perdas começam no campo por ocasião da colheita e no preparo do produto para comercialização; prosseguem nas centrais de abastecimento e outros atacadistas; e, por fim, na rede varejista e consumidores intermediários e finais (VILELA et al., 2003).

Durante o processo de produção, 0 desperdício pode ocorrer pela falta de estudo e planejamento quanto à época e quantidade, condições de mercado e escolha de variedade compatível com 0 solo e 0 clima local. $\mathrm{Na}$ fase de colheita, por sua vez, máquinas sem a devida manutenção, espaçamento irregular entre os sulcos de terra, ferramentas inadequadas e trabalhadores despreparados são os aspectos que contribuem para 0 aumento do problema (VASCONCELOS, 2008).
Na fase de implantação das culturas, diminuem grandemente as perdas (pré-colheita), os fatores ambientais ou climáticos que, em conjunto com manejo do solo, são de grande importância para a obtenção de produtos com qualidade (MARTINS; FARIAS, 2002).

Outro fator que contribui para a situação exposta é 0 transporte dos frutos da área de plantio para a comercialização, que muitas vezes é realizado em caixas não apropriadas com uma quantidade excessiva de alimentos, ocasionando alto nível de perda na produção (Figura 1).

Como afirma Vasconcelos (2008), a segunda maior causa de desperdício encontra-se entre o produtor e o comerciante, onde é realizada a embalagem, 0 transporte e 0 armazenamento dos produtos. A influência da embalagem usada é determinante para resultados positivos, pois cada produto deve ter uma embalagem apropriada que se adeque às necessidades do produto. As embalagens não devem conter um número excessivo de unidades, tampouco devem provocar danos nos mesmos, pois, uma vez danificado, 0 alimento entra em um processo de deterioração mais rápido, e as reações químicas e bioquímicas que ocorrem em alguns levam os outros a se deteriorarem também provocando uma cadeia de desperdício.

As perdas ocorridas no transporte variam de 


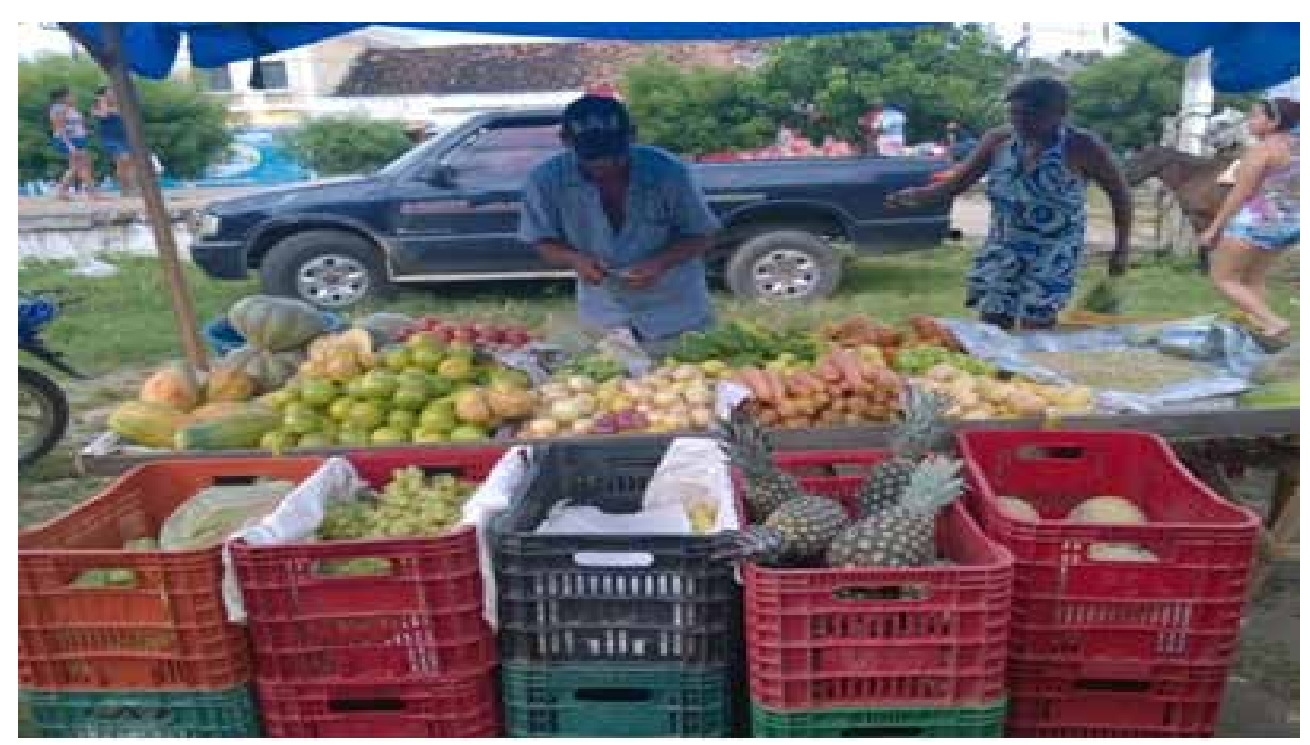

Figura 1. Utilização de caixas plásticas para o transporte do campo à feira livre em Capistrano-CE Fonte: Autor.

acordo com as estações do ano, sendo mais intensas nas épocas chuvosas. Ademais, o mau estado de conservação das estradas brasileiras, associado às altas temperaturas existentes do país, aceleram a deterioração, de forma que as perdas de produtos perecíveis, como hortaliças, podem chegar a $30 \%$ (CAIXETA FILHO, 1999).

Prim (2003) analisa o desperdício nas fases de transporte e de comercialização dos produtos propondo que, a fim de se evitar desperdícios, cada produto deve ser individualmente estudado, conforme suas características. No transporte devem ser consideradas a rapidez e a temperatura, pois alguns vegetais quando mantidos a temperaturas altas se deterioram em um período de tempo muito curto, o que pode ser incompatível com o tempo de transporte.

É na fase de comercialização que ocorrem os maiores desperdícios dos alimentos, principalmente pela inadequação de armazenagem, pela exposição do produto ao sol ou à umidade excessiva, pela falta de cuidado com os produtos expostos e no manuseio pelos consumidores (Figuras 2 e 3 ).

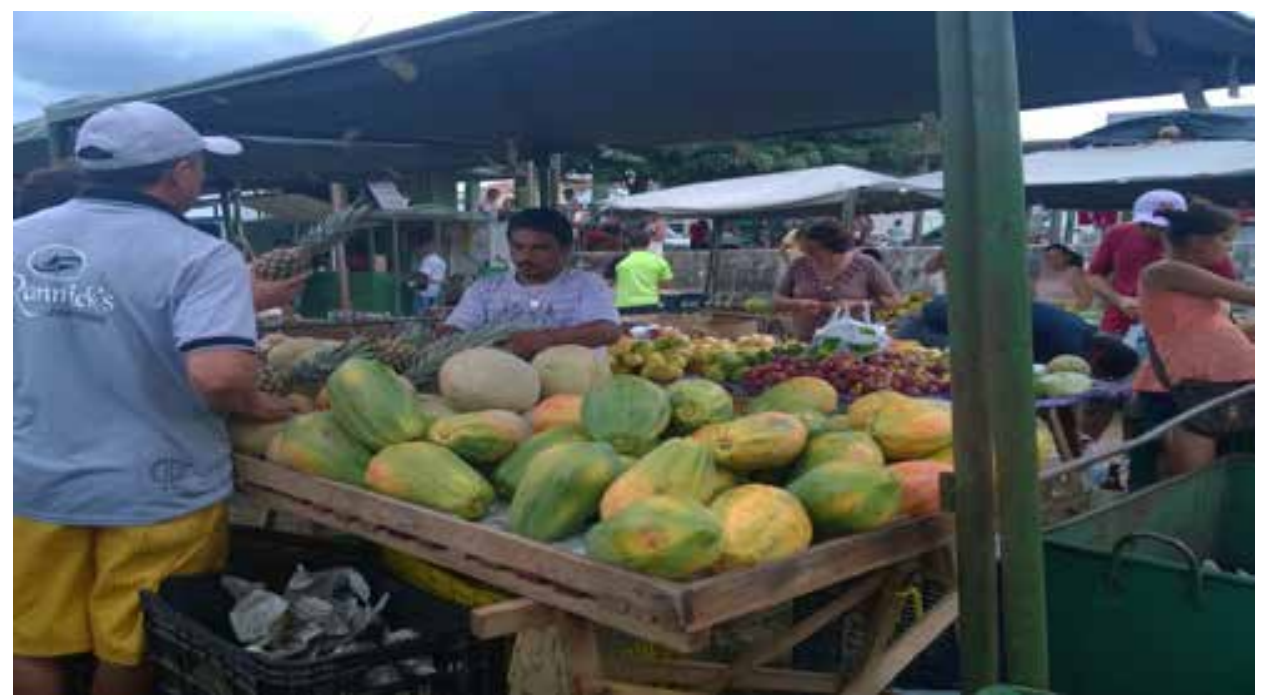

Figura 2. Exposição dos produtos a variações de temperatura, umidade e radiação solar na feira livre em Capistrano, CE Fonte: Autor 


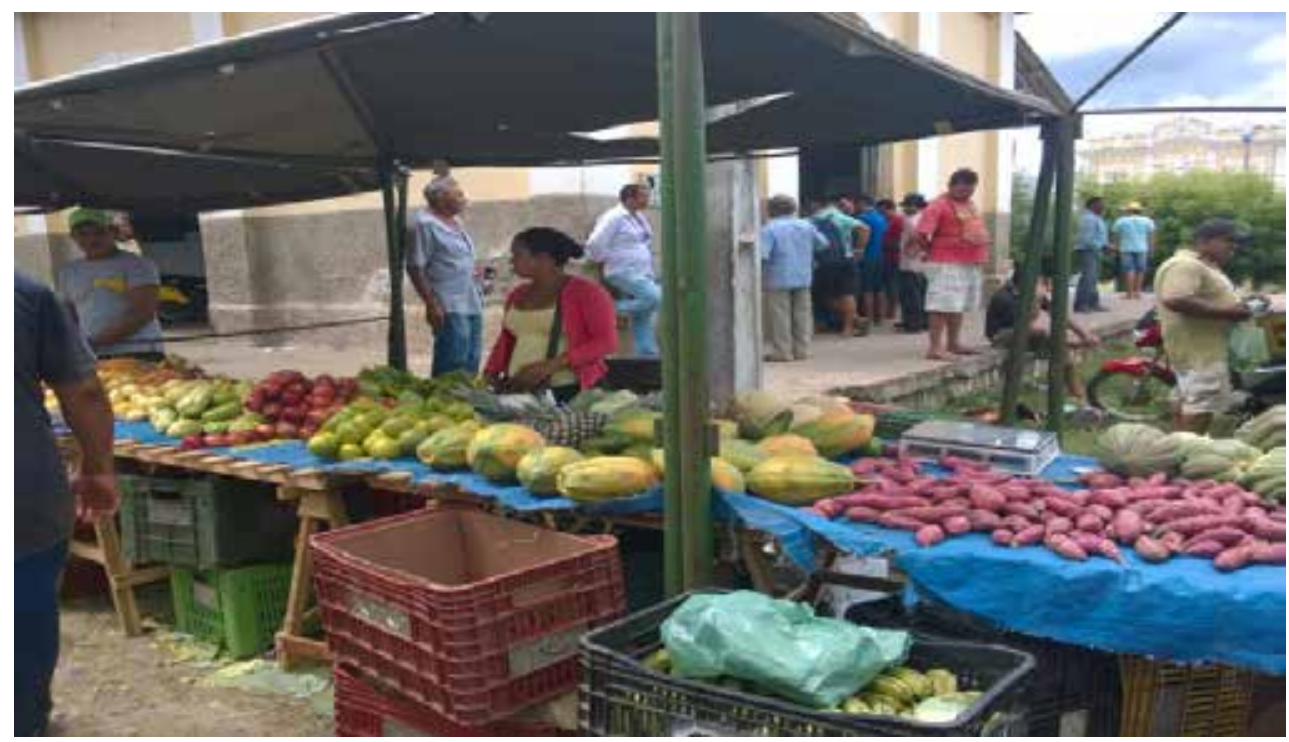

Figura 3. Distribuição inadequada de frutas e verduras comercializadas na feira em Capistrano, CE Fonte: Autor

Todavia, os frutos danificados fisicamente em decorrência da colheita e do transporte não são aceitos pelos consumidores. Havendo desperdício generalizado, sendo na maioria das vezes jogados no lixo e raramente reaproveitado para alimentação animal, em discordância ao que Martins e Farias (2002) propõem que, quanto ao material descartado, poderia ser feito sempre que possível 0 aproveitamento com 0 devido processamento destes produtos, o que acarretaria em grandes economias e geração de renda extra ao processo.

As frutas encontradas no município de Capistrano possuem grande potencial de mercado, sendo destinadas ao CEASA e à feira da agricultura familiar realizada na própria cidade. A Figura 4 mostra a forma de organização e distribuição dos hortícolas comercializados na feira da agricultura familiar. Nesta, grande parte das perdas se dá na comercialização, por vários fatores, como afirma Chitarra; Chitarra (2005) ao explicar que as centrais de distribuição dos produtos hortícolas são também um local de aumento das perdas pós-colheita. São usualmente locais muito frequentados e superpopulosos, com ausência ou condições necessárias de sanificação; faltam facilidades apropriadas para expor, armazenar, amadurecer, carregar e descarregar os produtos. Os comerciantes usualmente dispõem de produtos que acumularam danos nas etapas subsequentes da cadeia de comercialização. Nessa etapa a deterioração encontra-se em fase progressiva. 


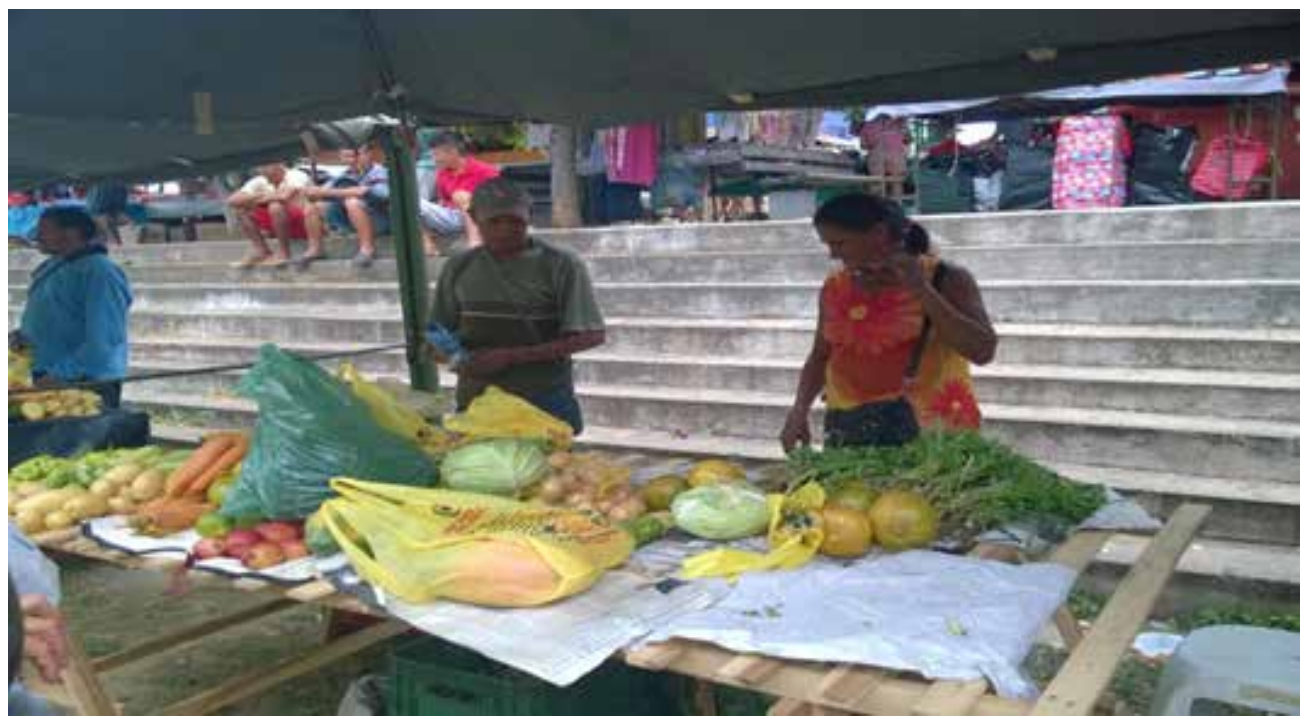

Figura 4. Logística de organização dos hortifrútis comercializados na feira livre em Capistrano, CE Fonte: autor.

Com isso, as perdas pós-colheita geram graves consequências econômicas e sociais, por proporcionarem variação no comportamento do mercado, induzindo mudanças importantes nos parâmetros econômicos. Desta forma, 0 aumento de perdas faz com que a quantidade de equilíbrio de mercado diminua e o preço de equilíbrio cresça. Quando o preço de equilíbrio de mercado cresce, ocorre redução no excedente do consumidor. Neste caso, 0 consumidor paga o custo das perdas que é embutido no preço final do produto. De forma geral, qualquer nível de perdas é prejudicial para os consumidores (VILELA et al., 2003).

Para que as perdas e desperdícios sejam reduzidos é necessário trabalho de conscientização junto aos agentes envolvidos na cadeia produtiva de hortifrútis. Nesse sentido, sugere-se uma campanha educativa como forma de estímulo à adoção de tecnologias de redução de perdas e desperdícios, proporcionando treinamentos aos produtores. Além disso, é necessária a educação dos consumidores tanto no âmbito institucional como doméstico, para que se conscientizem da importância de se reduzir perdas e desperdícios. (VILELA et al., 2003).

A escolha na hora da compra é um dos fatores que contribui para o reaproveitamento dos alimentos. De modo que se esperam trabalhos de conscientização e manipulação correta sobre os alimentos, visando diminuir o desperdício no setor de hortifrúti, diminuindo custos e resíduos alimentares no meio ambiente, e contribuir para uma vida mais saudável da população (GOULART, 2008).

Nesse sentido, percebe-se que não é dada a real importância da dimensão das cadeias produtivas, sendo inclusive, pouco valorizada pelas políticas agrícolas nacionais, que enfatizam, via aumento da produtividade dos fatores de produção em detrimento da qualidade, havendo significativos aumentos da produção bruta por hectare cultivado e não o incremento à oferta líquida de alimentos para o consumo final. É na esfera da distribuição que ocorrem os maiores índices de perdas alimentares, anulando parcialmente os enormes esforços produtivos baseados em ganhos de produtividade agrícola (BELIK; CUNHA; COSTA, 2012).

\section{CONCLUSÃO}

A partir desse estudo foi possível identificar que a perda dos alimentos pode estar relacionada direta ou indiretamente a vários fatores que ocorrem ao longo de toda a cadeia produtiva dos hortifrútis. As perdas encontradas no início do processo, ou seja, no campo, poderiam ser minimizadas com a utilização de 
planejamento prévio e treinamento da mão de obra, assim como a utilização de técnicas que propiciem um alto desempenho produtivo. Essa informação sugere a necessidade de maiores investimentos em treinamento de capacitação técnica para os encarregados do setor de frutas e hortaliças da região.

Evidenciaram-se maiores perdas na feira, onde os índices de desperdícios são bastante elevados e preocupantes, ocorrendo perdas no armazenamento, nas embalagens utilizadas, no transporte, na venda, e na forma de exposição dos alimentos; contudo, há algumas medidas simples que, se adotadas, poderiam ser capazes de eliminar boa parte desse desperdício, tais como: armazenamento e embalagens adequadas e correta manipulação e exposição dos produtos. 0 desperdício também está associado à falta de informação da população, elevando cada vez mais 0 custo dos alimentos para os consumidores.

\section{REFERÊNCIAS}

BARROS, M.S. Mercado varejista de gêneros alimentícios da Grande São Paulo: uma abordagem estrutural. São Paulo: Secretaria de Agricultura, 1978. 52p. (Relatório de pesquisa, 03/78).

BELIK, W.; CUNHA, A. R. A. A.; COSTA, L. A. Crise dos alimentos e estratégias para a redução do desperdício no contexto de uma política de segurança alimentar e nutricional no brasil. Planejamento e Políticas públicas, Brasília, v. 38, p.107-132, jun. 2012.

BICALHO, A. H.; LIMA, V. O. B. Redução do desperdício em uma Unidade de Alimentação e Nutrição. Nutr. J. Brazilian Soc. Food Nutr., v.38, n.3, p. 269-277, 2013.

CAIXETA FILHO, J.V. Losses in the transportation of fruits and vegetables: A Brazilian case study. International Journal of logistics: Research and applications, v. 2, n. 3, 1999.

CENCI, S.A. Perdas pós-colheita de Frutos e Hortaliças. Rio de Janeiro: EMBRAPA/CTAA, 2000.
CHITARRA, M. I. F.; CHITARRA, A. B. Pós-colheita de frutas e hortaliças: fisiologia e manuseio. Lavras: $\mathrm{Ed}$. da Ufla, 2005.

GIL, A.C. Como elaborar projetos de pesquisa. São Paulo: Atlas, 2002. 176p.

GOULART, R. M. M. Desperdício de alimentos um problema de saúde pública. Integração, São Paulo, v. 54, p. 285-288, set. 2008.

MARTINS, C. R.; FARIAS, R. M. Produção de alimentos $x$ desperdício: tipos, causas e como reduzir perdas na produção agrícola: revisão. Revista da Fzva, Uruguaiana, v. 9, n. 1, p.20-32, 2002.

MINAYO, M. C. S. Pesquisa social: teoria, método e criatividade. Petrópolis: Vozes, 2001. 80p.

NATIONAL ACADEMY OF SCIENCES. Pérdidas de post-cosecha de alimentos en países en desarrollo. Tradução de Gonzalo Roa. Viçosa: Centro Nacional de Treinamento em Armazenagem, 1982. 213p. (Série CENTREINAR, 4).

PRIM, M. B. S. Análise do Desperdício de partes vegetais consumíveis. 2003. 117f. Tese (Engenharia de Produção) - Universidade de Santa Catarina, Florianópolis, 2003.

RICARTE, M. P. R.; FÉ, M. A. B. M.; SANTOS, I. H. V. S.; LOPES, A. K. M. Avaliação do desperdício de alimentos em uma Unidade de Alimentação e Nutrição Institucional em Fortaleza-CE. Saber científico, v.1, n.1, p.158-175, 2008.

ROCHA, T. S.; SOUSA, E. C.; SOUSA, A. V. R. A cultura do desperdício de alimentos e seus impactos na sociedade: estudo de revisão. In: SIMPÓSIO DE PRODUTIVIDADE EM PESQUISA, 2; ENCONTRO DE INICIAÇÃO CIENTÍFICA DO IFPI - ENCIPRO, 2., 2009. Anais... Instituto Federal do Piauí, 2009.

TRIVIÑOS, A. N. S. Introdução à pesquisa em ciências sociais: a pesquisa qualitativa em educação. São Paulo: Atlas, 1987. 
VASCONCELOS, E. G. M. Redução de desperdício de alimentos com a produção de refeições para pessoas carentes - Estudo de caso. 2008. $68 \mathrm{f}$. Monografia (Especialização em gastronomia e saúde) - Universidade de Brasília, Brasília, 2008.

VILELA, N. J. et al. 0 peso da perda de alimentos para a sociedade: 0 caso das hortaliças. Horticultura Brasileira, Brasília, v. 21, n. 2, p.141-143, jun. 2003.

Recebido em: 31 de março de 2017 Aceito em: 29 de maio de 2017 